\title{
Vomiting in pregnancy is associated with a higher risk of low birth weight: a cohort study
}

Clive J. Petry ${ }^{1 *}$ D, Ken K. Ong ${ }^{1,2,3}$, Kathryn Beardsall ${ }^{1}$, leuan A. Hughes ${ }^{1}$, Carlo L. Acerini ${ }^{1}$ and David B. Dunger ${ }^{1,3}$

\begin{abstract}
Background: Low birth weight has important short- and long-term health implications. Previously it has been shown that pregnancies affected by hyperemesis gravidarum in the mother are at higher risk of having low birth weight offspring. In this study we tested whether such risks are also evident with less severe nausea and vomiting in pregnancy.
\end{abstract}

Methods: One thousand two hundred thirty-eight women in the prospective Cambridge Baby Growth Study filled in pregnancy questionnaires which included questions relating to adverse effects of pregnancy and drugs taken during that time. Ordinal logistic regression models, adjusted for parity, ethnicity, marital and smoking status were used to relate the risk of giving birth to low birth weight $(<2.5 \mathrm{~kg})$ babies to nausea and/or vomiting in pregnancy that were not treated with anti-emetics and did not report suffering from hyperemesis gravidarum.

Results: Only three women in the cohort reported having had hyperemesis gravidarum although a further 17 women reported taking anti-emetics during pregnancy. Of those 1218 women who did not take anti-emetics 286 (23.5\%) did not experience nausea or vomiting, 467 (38.3\%) experienced nausea but not vomiting and 465 experienced vomiting (38.2\%). Vomiting during pregnancy was associated with higher risk of having a low birth weight baby (odds ratio $3.5(1.2,10.8), p=0.03)$. The risk associated with vomiting was found in the first $(p=0.01)$ and second $(p=0.01)$ trimesters but not the third $(p=1.0)$. The higher risk was not evident in those women who only experienced nausea (odds ratio $1.0(0.3,4.0), p=1.0)$.

Conclusions: Vomiting in early pregnancy, even when not perceived to be sufficiently severe to merit treatment, is associated with a higher risk of delivering a low birth weight baby. Early pregnancy vomiting might therefore be usable as a marker of higher risk of low birth weight in pregnancy. This may be of benefit in situations where routine ultrasound is not available to distinguish prematurity from fetal growth restriction, so low birth weight is used as an alternative.

Keywords: Hyperemesis gravidarum, Nausea, Anti-emetic, Small for gestational age

\section{Background}

Low birth weight (LBW) leads to a higher risk of perinatal mortality and morbidity, including impaired growth and cognitive development [1]. More long-term complications include higher risks for high blood pressure [2] and cardiovascular disease [3], impaired glucose tolerance and type 2 diabetes [4], early age at menarche

\footnotetext{
*Correspondence: cjp1002@cam.ac.uk

'Department of Paediatrics, University of Cambridge, Box 116, Cambridge

Biomedical Campus, Hills Road, Cambridge CB2 OQQ, UK

Full list of author information is available at the end of the article
}

[5] and menopause [6], and reduced bone mineral density [7] and osteoporosis [8]. LBW can relate to one or both of premature birth and fetal growth restriction, or being constitutionally small, and risk of LBW can be related to such factors as ethnic differences, multiple birth pregnancies, maternal age at birth, fetal environmental factors such as exposure to alcohol, smoking or illicit drugs, maternal nutrition during pregnancy, poor socioeconomic status [9] and genetic defects [10]. Another risk factor appears to be hyperemesis gravidarum [11-13], a severe form of nausea and vomiting in pregnancy that can

(C) The Author(s). 2018 Open Access This article is distributed under the terms of the Creative Commons Attribution 4.0 International License (http://creativecommons.org/licenses/by/4.0/), which permits unrestricted use, distribution, and 
lead to maternal dehydration and weight loss. Treatment of severe nausea and vomiting in pregnancy with antiemetics may even be associated with a reduction in the prevalence of LBW $[14,15]$, although such findings are by no means universal [16-18].

Whilst the association between hyperemesis gravidarum and higher risk of LBW is reasonably well established, what is not so clear is whether potentially less severe nausea and/or vomiting in pregnancy is also associated with the risk of delivering LBW babies. The only recent related evidence suggests that it may be associated with being small for gestational age (SGA) due to fetal growth restriction, one of the main reasons for a baby having a LBW [19]. This study was therefore designed to test the hypothesis that nausea and vomiting in pregnancy, of insufficient severity to require treatment, is associated with the risk of delivering a LBW baby. To do this we used data collected for the Cambridge Baby Growth Study.

\section{Methods \\ Cohort}

The prospective and longitudinal Cambridge Baby Growth Study recruited 2229 mothers (and their partners and offspring) attending ultrasound clinics during early pregnancy at the Rosie Maternity Hospital, Cambridge, United Kingdom, between 2001 and 2009 [20]. All mothers were over 16 years of age. Birth weights of their babies, their sex and their gestational age at birth were extracted from hospital notes, having been recorded there by midwives. $\mathrm{LBW}$ was defined as a birth weight of less than $2.5 \mathrm{~kg}$. SGA was classified as being in the lowest tenth percentile for gestational age. Prematurity was defined as being born prior to week 37 of gestation. Categorisation according to whether or not the participants developed gestational diabetes [21] or gestational hypertension [22] has been described previously. In this cohort, $96.9 \%$ of the offspring were of white ethnicity, $0.8 \%$ were of mixed race, $0.6 \%$ were black (African or Caribbean), 0.8\% were East-Asian, and $0.9 \%$ were Indo-Asian.

Each of the study participants was given a printed questionnaire at recruitment with questions to answer and return once the pregnancy was completed [23]. They were encouraged to fill it in as the pregnancy progressed. The questionnaires included boxes to tick if the participants had experienced nausea or had vomited during pregnancy. If either of these boxes were ticked there were further boxes to fill in concerning the timing (i.e. week(s) of pregnancy) when the nausea or vomiting were experienced. A further question asked "Have you taken any medicine during this pregnancy?" Those women who responded in the affirmative were then asked to complete a table with the following headings:
"Name", "Disease", "Daily Dose", "No. of Days" and "Gestational Week(s)". This means that nausea and vomiting prior to attending the booking clinic would have had to have been recalled over a maximum period of several weeks whereas nausea and vomiting subsequent to that could be recorded as the pregnancy progressed (requiring recollection over a much shorter period of time). A total of 1238 women (54.6\%) filled in the questionnaires; those that did not were excluded from the present analysis. For 598 of the pregnancies where the mother failed to return a filled-in questionnaire the baby's birth weight was also missing. The birth weights of the remaining babies, adjusted for prepregnancy maternal BMI, gestational age at birth, parity and sex, were not different between those that completed the questionnaire and those that did not (filled in questionnaire $3.482(3.456,3.508) \mathrm{kg} \mathrm{v}$. did not fill in questionnaire $3.403(3.310,3.497) \mathrm{kg}, p=0.1)$, although the prevalence of LBW in the offspring of the women that returned the questionnaires was lower (filled in questionnaire $37 / 1218 \mathrm{v}$. did not fill in questionnaire $27 / 431, p=5 \times 10^{-3}$ ). Of those women that filled in their questionnaires only 3 reported that they had hyperemesis gravidarum and a further 17 were treated with anti-emetics: cyclizine (7), promethazine (5), prochlorperazine (4), metoclopramide (2), domperidone (2), prednisolone (2), chlorphenamine (1), ondansetron (1), chlorpromazine (1) and unknown (1). These 20 women were excluded from this specific analysis in order to test only those women who had a potentially milder phenotype. The self-reported timings of exposure to nausea and/or vomiting were divided into trimesters (first trimester being up to gestational week 12 , second trimester being weeks 13 to 27 and third trimester being from week 28 onwards).

\section{Categorisation and calculations}

We categorised each of the women into one of three different groups: those who reported neither nausea nor vomiting $(n=286)$, those who reported nausea but not vomiting $(n=467)$ and those who reported vomiting ( $n=465,432$ of whom reported nausea and vomiting and 33 who reported vomiting without nausea). Those that reported vomiting without nausea had no evidence of concurrent urinary or chest infections, or evidence of the vomiting occurring just in the final trimester of pregnancy. The body mass indexes (BMI) were calculated dividing the maternal weights prior to pregnancy by their heights squared.

\section{Statistical analysis}

Associations with LBW were adjusted for the following confounders: parity, marital and smoking statuses, and ethnicity [24]. Associations between nausea and vomiting 
and quantitative continuous variables (such as BMI and maternal age) were tested using linear regression models (adjusted for confounders where necessary). Associations with dichotomous variables (such as LBW) were tested using ordinal logistic regression (adjusted for confounders where necessary), the $x^{2}$-test or Fisher's exact test as appropriate. Unless otherwise stated all other data are presented as means (95\% confidence intervals (CI)). Statistical analyses were performed using Stata 13 (StataCorp LP, College Station, Texas, U.S.A.). $P<0.05$ was considered statistically significant throughout.

\section{Results}

\section{Maternal clinical characteristics}

Table 1 shows the clinical characteristics of the different groups tested. Those 465 women who experienced vomiting during pregnancy (432 of whom also reported nausea) tended to be younger $\left(p=1.5 \times 10^{-3}\right)$ and slightly heavier/more obese (pre-pregnancy weight $p=0.02$, pre-pregnancy BMI $p=0.01$ ) than those women who did not experience nausea or vomiting in pregnancy. These differences in clinical characteristics from those women who did not experience nausea or vomiting, were not evident in those women who experienced nausea but not vomiting.

\section{Associations between maternal exposure to nausea and/ or vomiting in pregnancy and birth characteristics of the baby}

The delivery of LBW babies was more common in those women who experienced vomiting in pregnancy (when adjusted for confounders) than in those women who did not experience vomiting or nausea $(p=0.03$; Table 2$)$. This relationship was still evident after further adjustment was made for maternal BMI prior to pregnancy (OR 3.1 (1.0, 9.7), $p=0.048)$. In contrast there was no higher risk of LBW associated with experiencing nausea but not vomiting in pregnancy $(p=1.0)$.

Table 2 shows other birth characteristics of women according to their experience of nausea and vomiting in pregnancy. Despite the differences in risk of LBW, there was no apparent difference in mean birth weight, gestational age at birth or prevalence of prematurity or SGA. Similarly there was no apparent difference in the birth weight adjusted for pre-pregnancy maternal BMI, gestational age at birth, sex and parity. However there was a slightly higher proportion of female babies born to mothers who experienced vomiting during pregnancy. Figure 1 shows Kernel density estimation plots for unadjusted birth weight, gestational age at birth and birth weight for gestational age according to maternal exposure to nausea and vomiting in pregnancy. Small differences in the distributions of these were evident in each plot.

\section{Associations between exposure to vomiting in different trimesters of pregnancy and birth characteristics of the baby}

The higher prevalence of giving birth to LBW babies in women who experienced vomiting was evident in those who experienced it in the first (OR $4.3(1.4,13.2), p=0.01$, $n=266$ vomiting and $n=204$ no nausea or vomiting) or second (OR 4.4 $(1.4,13.9), \mathrm{p}=0.01, n=185$ vomiting and $\mathrm{n}=204$ no nausea or vomiting) trimester of pregnancy. However it was not evident in those who experienced it in the third trimester (OR $1.0(1.0,1.0), n=36$ vomiting and 204 no nausea or vomiting, $p=1.0$ ).

Table 1 Characteristics of the pregnant women in the Cambridge Baby Growth Study who returned their questionnaires categorised according to whether or not they experienced nausea or vomiting in pregnancy

\begin{tabular}{|c|c|c|c|}
\hline Characteristic & No Nausea or Vomiting & Nausea alone & Vomiting \\
\hline$n$ & 286 & 467 & 465 \\
\hline Age (years) & $\begin{array}{l}34.2 \\
(33.7,34.6)\end{array}$ & $\begin{array}{l}33.6 \\
(33.4,33.9)\end{array}$ & $\begin{array}{l}33.1^{* * *} \\
(32.7,33.4)\end{array}$ \\
\hline Height (m) & $\begin{array}{l}166.1 \\
(165.3,166.8)\end{array}$ & $\begin{array}{l}165.9 \\
(165.5,166.3)\end{array}$ & $\begin{array}{l}165.7 \\
(165.1,166.4)\end{array}$ \\
\hline Pre-pregnancy weight (kg) & $\begin{array}{l}65.0 \\
(63.6,66.4)\end{array}$ & $\begin{array}{l}66.1 \\
(65.3,66.9)\end{array}$ & $\begin{array}{l}67.1^{*} \\
(66.0,68.3)\end{array}$ \\
\hline Pre-pregnancy BMI (kg/m²) & $\begin{array}{l}23.6 \\
(23.1,24.1)\end{array}$ & $\begin{array}{l}24.0 \\
(23.7,24.3)\end{array}$ & $\begin{array}{l}24.5^{*} \\
(24.0,24.9)\end{array}$ \\
\hline Weight gain during pregnancy (kg) & $\begin{array}{l}7.9 \\
(7.1,8.7)\end{array}$ & $\begin{array}{l}8.2 \\
(7.7,8.6)\end{array}$ & $\begin{array}{l}8.4 \\
(7.7,9.1)\end{array}$ \\
\hline Smoked during pregnancy (\%) & 4.2 & 1.9 & 4.6 \\
\hline Developed gestational diabetes (\%) & 10.6 & 9.6 & 9.6 \\
\hline Developed gestational hypertension (\%) & 6.9 & 4.2 & 7.2 \\
\hline
\end{tabular}

${ }^{*} \mathrm{P}<0.05,{ }^{* *} P<0.01,{ }^{* * *} P<0.001$ compared with the no nausea or vomiting group. Data are mean $(95 \% \mathrm{Cl})$. None of these women were treated with anti-emetics during pregnancy. Nausea alone refers to those women who experienced nausea in pregnancy but not vomiting. Vomiting refers to those women who experienced vomiting during pregnancy, independently of whether or not they also experienced nausea 
Table 2 Birth related factors of babies of women in the Cambridge Baby Growth Study who returned their questionnaires, categorised according to whether they experienced nausea or vomiting in pregnancy

\begin{tabular}{|c|c|c|c|}
\hline Birth-related Factor & No Nausea or Vomiting & Nausea alone & Vomiting \\
\hline $\bar{n}$ & 286 & 467 & 465 \\
\hline Parity (n) & $\begin{array}{l}1.7 \\
(1.6-1.8)\end{array}$ & $\begin{array}{l}1.8 \\
(1.7-1.8)\end{array}$ & $\begin{array}{l}1.8^{*} \\
(1.8-1.9)\end{array}$ \\
\hline Birth weight (kg) & $\begin{array}{l}3.512 \\
(3.459,3.565)\end{array}$ & $\begin{array}{l}3.504 \\
(3.474,3.534)\end{array}$ & $\begin{array}{l}3.496 \\
(3.453,3.540)\end{array}$ \\
\hline Adjusted birth weight (kg) & $\begin{array}{l}3.494 \\
(3.449,3.539)\end{array}$ & $\begin{array}{l}3.499 \\
(3.474,3.525)\end{array}$ & $\begin{array}{l}3.505 \\
(3.468,3.541)\end{array}$ \\
\hline LBW (n/total (\%)) & $\begin{array}{l}6 / 277 \\
(2.2 \%)\end{array}$ & $\begin{array}{l}9 / 461 \\
(2.0 \%)\end{array}$ & $\begin{array}{l}21 / 460^{*} \\
(4.6 \%)\end{array}$ \\
\hline LBW (OR) & Ref. & $\begin{array}{l}1.0 \\
(0.3-4.0)\end{array}$ & $\begin{array}{l}3.5^{*} \\
(1.2-10.8)\end{array}$ \\
\hline LBW (OR) first trimester nausea or vomiting & & $\begin{array}{l}2.1 \\
(0.8-5.7)\end{array}$ & $\begin{array}{l}4.3^{*} \\
(1.4-13.2)\end{array}$ \\
\hline LBW (OR) second trimester nausea or vomiting & & $\begin{array}{l}4.2^{*} \\
(1.7-10.1)\end{array}$ & $\begin{array}{l}4.4^{*} \\
(1.4-13.9)\end{array}$ \\
\hline LBW (OR) third trimester nausea or vomiting & & $\begin{array}{l}1.5 \\
(0.3-6.7)\end{array}$ & $\begin{array}{l}0.8 \\
(0.1-7.0)\end{array}$ \\
\hline Gestational age at birth (weeks) & $\begin{array}{l}39.9 \\
(39.8,40.1)\end{array}$ & $\begin{array}{l}39.9 \\
(39.8,40.0)\end{array}$ & $\begin{array}{l}39.8 \\
(39.7,39.9)\end{array}$ \\
\hline $\begin{array}{l}\text { Prematurity } \\
(\mathrm{n}(\%))\end{array}$ & $\begin{array}{l}4 \\
(1.4)\end{array}$ & $\begin{array}{l}7 \\
(1.5)\end{array}$ & $\begin{array}{l}11 \\
(2.3)\end{array}$ \\
\hline $\begin{array}{l}\text { SGA } \\
(\mathrm{n}(\%))\end{array}$ & $\begin{array}{l}11 \\
(3.9)\end{array}$ & $\begin{array}{l}16 \\
(3.5)\end{array}$ & $\begin{array}{l}25 \\
(5.2)\end{array}$ \\
\hline $\begin{array}{l}\text { Sex of the baby } \\
\text { (n (\%) male) }\end{array}$ & $\begin{array}{l}161 \\
(56.9 \%)\end{array}$ & $\begin{array}{l}236 \\
(51.1 \%)\end{array}$ & $\begin{array}{l}225 \\
(49.9 \%)^{*}\end{array}$ \\
\hline
\end{tabular}

\section{Discussion}

Vomiting in pregnancy, not treated with anti-emetics, is associated with a higher risk of giving birth to LBW babies in this study. This is consistent with reported associations between LBW (or related phenotypes such as SGA) and hyperemesis gravidarum [11-13, 25-28], although such associations are not universal findings [29-32]. Nausea and vomiting with no reference to hyperemesis gravidarum has also been associated with a higher risk of LBW [33] and decreased birth weight [34] in some other studies, although no difference in risk was reported in others [19, 35-37]. Although a systematic review [38] reported a lower risk of LBW in association with nausea and vomiting in pregnancy the studies that it was based looked at anti-emetic use to categories study participants [14, 15]. This is therefore very different to our own study where we specifically excluded women who took anti-emetics in case these drugs affected pathways involved in regulating LBW risk [39]. Similarly the very large Norwegian Mother and Child Cohort Study [40] found reduced population rates of LBW in association with nausea and vomiting in pregnancy, but did so without specifically excluding those women who took antiemetics in pregnancy. Our study therefore presents results a slightly different population to those examined in other investigations, and one where we specifically investigated a potentially milder negative aspect of pregnancy than hyperemesis gravidarum.

This higher risk for LBW associated with vomiting, and nausea but just in the second trimester, appeared to be in the first two trimesters of pregnancy with an apparent lack of risk in the third trimester. Studies are ongoing to try and discover whether or not nausea and vomiting in pregnancy and resulting associations are genetically mediated [41, 42]. With an overall odds ratio of 3.5 for LBW in our population, vomiting in early pregnancy may be a marker of risk for LBW that is useful for its prediction in conjunction with other risk factors. Where routine ultrasound is available small babies tend to be assessed as either SGA (possibly due to fetal growth restriction) and/or premature rather than LBW, but the link with vomiting may be useful in areas where such scans are not available and LBW is used to 

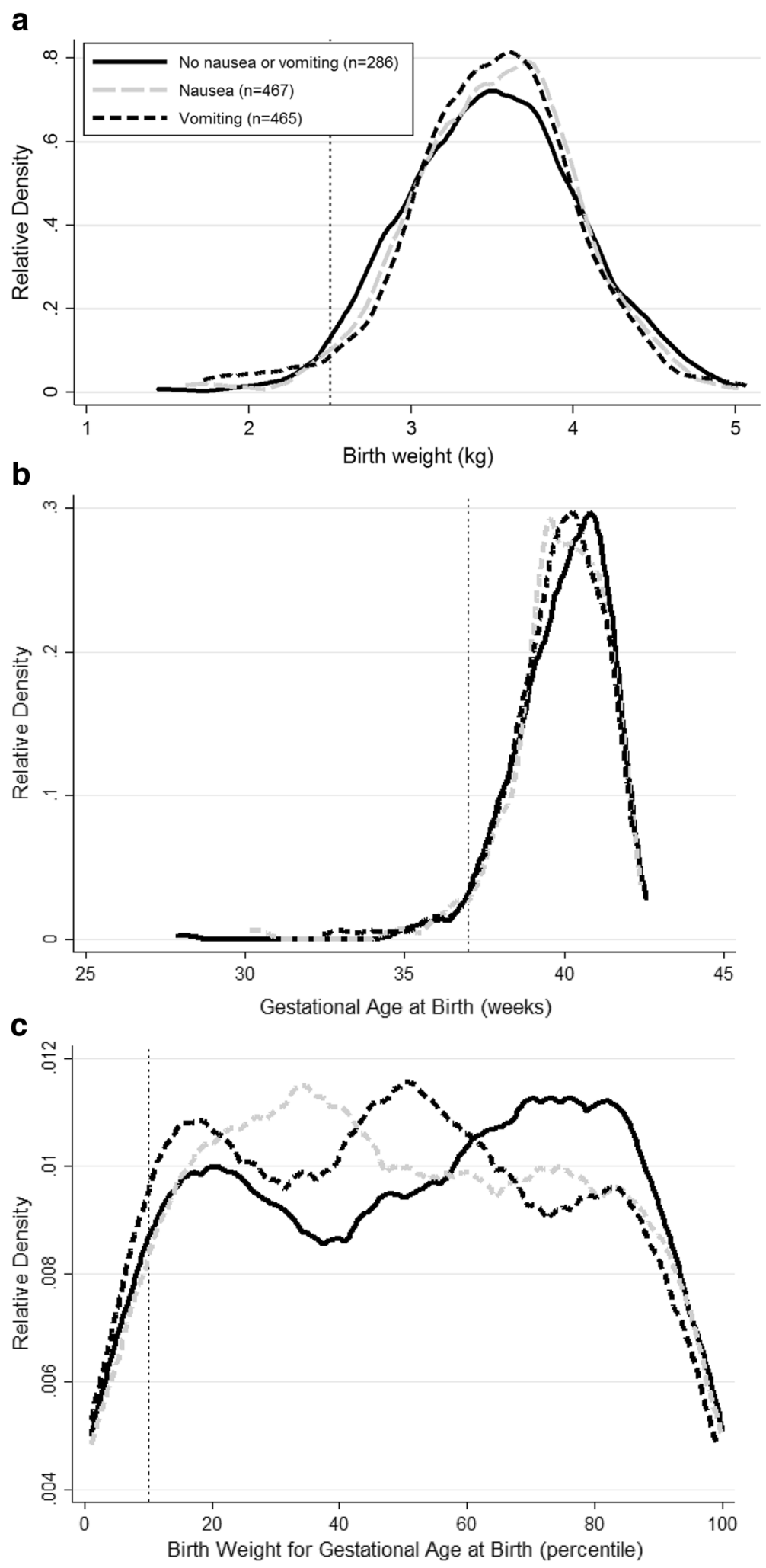

Fig. 1 (See legend on next page.) 
(See figure on previous page.)

Fig. 1 Kernel density estimation plots of a unadjusted birth weight distributions, $\mathbf{b}$ gestational age at birth and $\mathbf{c}$ birth weight adjusted for gestational age at birth percentiles in the Cambridge Baby Growth Study in babies whose mothers were not treated with anti-emetics in pregnancy. The lines are plotted according to the mother's exposure to nausea or vomiting in pregnancy. The cut off for LBW is shown by the dotted line at $2.5 \mathrm{~kg}$ in (a), that for prematurity is shown by the dotted line at 37 weeks in (b) and that for SGA is shown by the dotted line at the tenth percentile of birth weight adjusted for gestational age at birth in (c). Nausea refers to those women who experienced nausea but not vomiting during pregnancy. Vomiting refers to those women who experienced vomiting during pregnancy, independently of whether or not they also experienced nausea

encompass them both. Nausea and vomiting in pregnancy are thought to be protective towards the embryo/ fetus in terms of reducing exposure to food borne harmful substances such as infective microorganisms [43], and they can lead to changes in the maternal dietary intake [44]. There is evidence that this can lead to positive effects on the fetus such as decreased rates of miscarriage and congenital malformations [45]. Whilst potentially being an advantage in a mild form, in excess it is possible that this vomiting might reduce nutrient delivery to the fetus leading to the greater risk of LBW [46]. The fact that in our population as a whole there was no apparent decrease in mean birth weight despite the higher prevalence of LBW suggests that whilst there is a negative impact of vomiting on birth weight for some babies, in other babies a protective advantage may be evident [43]. The Kernel density estimation plot for birth weight in our population (Fig. 1(a)) would appear to be consistent with this suggestion (as birth weight density around the mean appeared to be higher in those women affected by vomiting).

LBW often relates to the baby undergoing fetal growth restriction and/or being born prematurely. Given the increase in birth weight usually observed in male babies, in general there is also a slightly increased risk of LBW in female babies compared to males [9]. In our population despite the association between vomiting and LBW, we did not find further significant independent associations between exposure to vomiting in pregnancy and the prevalence of SGA (a group that may have been enriched with babies who underwent fetal growth restriction) or premature births or the gestational age at birth. Looking at the Kernel density estimation plots for birth weight in our population below the cut off for LBW the line for women who experienced vomiting was clearly a little higher than those representing the other groups (Fig. 1(a)). The differences between the groups below the cut offs in the gestational ages at birth (to assess the densities related to prematurity) and the birth weights for gestational age (to assess the densities related to SGA) plots were smaller though (Fig. 1 (b) and (c)). Further studies are required to validate these findings in other cohorts, especially those that are better able to distinguish whether the LBW relates more to SGA (and therefore probably fetal growth restriction), prematurity or a mix of the two.
Whilst we could not ascribe the increased risk of LBW to fetal growth restriction or premature birth we did note a slight excess of pregnant women carrying female babies. This excess has previously been observed with hyperemesis gravidarum [47]. We recently reported that serum GDF-15 concentrations around week 15 of pregnancy were higher in those women reporting vomiting in the second trimester of pregnancy in the Cambridge Baby Growth Study [48], a hormone that may stimulate vomiting in pregnancy [49]. Interestingly we have also observed an increased concentration of week 15 serum GDF-15 concentrations in women carrying females compared to those carrying males in our population (Petry et al., unpublished observation), which may explain the slight excess of pregnant women carrying females in the group that experienced vomiting.

The main strengths of this study are its prospective nature and the fact that its design enabled us to study a group of women with a potentially milder, albeit still unpleasant phenotype than has been tested in other published studies. We have therefore uniquely been able to observe that the risk of giving birth to a LBW baby is higher with vomiting. The study's main limitation is that the nausea and vomiting and the taking of any anti-emetics to treat it were selfreported. The analysis could therefore have been affected by recall bias [50], although given that the women were encouraged to fill in their questionnaires as their pregnancies progressed rather than retrospectively the effects of this may have been limited. Indeed effects of any recall bias were clearly not sufficient to prevent us from discovering our association between increased circulating GDF-15 concentrations and second trimester vomiting [48]. Another limitation of our study may be a slight lack of statistical power to investigate potential effects of confounders. However there was clearly sufficient power in our study to test associations between the maternal experience of nausea and vomiting in pregnancy and the risk of delivering LBW babies. The final main limitation may be exclusion of women who took anti-emetics during pregnancy. This is because the threshold for nausea and vomiting where women sought and were then prescribed anti-emetics would have varied from participant to participant, and therefore the exclusion could have been rather selfselecting. However the advantage of doing this is the lack of potential confounding in our study of these drugs affecting pathways involved in regulating fetal growth, a strength of the study. 


\section{Conclusions}

This study suggests that vomiting in early pregnancy of insufficient severity to merit self-selected treatment with anti-emetics is associated with a higher risk of a woman giving birth to a LBW baby. It is possible that this vomiting may therefore be a marker of LBW pregnancies. This could be useful in situations where routine ultrasound is not available to distinguish prematurity from being SGA, so LBW is used as an alternative to encompass them both.

\section{Additional file}

Additional file 1: Description of data: the data that was associated with the manuscript entitled "Vomiting in pregnancy is associated with a higher risk of low birth weight: a cohort study" by Petry et al. (https:// doi.org/10.1186/s12884-018-1786-1) (XLSX 149 kb)

\section{Abbreviations}

BMI: Body mass index; Cl: Confidence interval; LBW: Low birth weight; OR: Odds ratio; SGA: Small for gestational age

\section{Acknowledgements}

We thank all the families that took part in the Cambridge Baby Growth Study, and we acknowledge the crucial role played by the research nurses especially Suzanne Smith, Ann-Marie Wardell and Karen Forbes, staff at the Addenbrooke's Wellcome Trust Clinical Research Facility, and midwives at the Rosie Maternity Hospital.

\section{Funding}

Funding for this study has come from the Wellbeing of Women (the Royal College of Obstetricians and Gynaecologists, UK) (RG1644). Other core funding has come from the Medical Research Council (7500001180), European Union Framework 5 (QLK4-1999-01422), the Mothercare Charitable Foundation (RG54608), Newlife Foundation for Disabled Children (07/20), and the World Cancer Research Fund International (2004/03). In addition, there has been support from National Institute for Health Research Cambridge Biomedical Research Centre. $\mathrm{KO}$ is supported by the Medical Research Council (Unit Programme number: MC_UU_12015/2). The sponsors did not have any role in the study design, in the collection, analysis or the interpretation of the data, in the writing of the manuscript or in the decision to submit it for publication.

\section{Availability of data and materials}

All data generated or analysed during this study are included in this published article [and its Additional file 1].

\section{Authors' contributions}

CP designed and analysed the data for this specific study and drafted the manuscript with $\mathrm{KB}$ and DD. KO, $\mathrm{H}, \mathrm{CA}$ and DD designed, established and oversee the Cambridge Baby Growth Study. All authors commented on the draft manuscript and read and approved the final manuscript.

\section{Ethics approval and consent to participate}

The Cambridge Baby Growth Study was approved by the Cambridge Local Research Ethics Committee, Addenbrooke's NHS Trust, Addenbrooke's Hospital, Cambridge, United Kingdom (Ref.: LREC 00/325). All procedures followed were in accordance with the institutional guidelines. Written informed consent was obtained from all the study participants.

\section{Competing interests}

The authors declare that they have no competing interests.

\section{Publisher's Note}

Springer Nature remains neutral with regard to jurisdictional claims in published maps and institutional affiliations.

\section{Author details}

'Department of Paediatrics, University of Cambridge, Box 116, Cambridge Biomedical Campus, Hills Road, Cambridge CB2 OQQ, UK. ${ }^{2}$ Medical Research Council Epidemiology Unit, University of Cambridge, Cambridge CB2 0QQ, UK. ${ }^{3}$ The Institute of Metabolic Science, University of Cambridge, Cambridge CB2 OQQ, UK

Received: 2 August 2017 Accepted: 26 April 2018

Published online: 04 May 2018

\section{References}

1. Pallotto EK, Kilbride HW. Perinatal outcome and later implications of intrauterine growth restriction. Clin Obstet Gynecol. 2006:49:257-69.

2. Barker DJ, Bull AR, Osmond C, Simmonds SJ. Fetal and placental size and risk of hypertension in adult life. BMJ. 1990;301:259-62

3. Barker DJ, Winter PD, Osmond C, Margetts B, Simmonds SJ. Weight in infancy and death from ischaemic heart disease. Lancet. 1989;2:577-80.

4. Hales CN, Barker DJ, Clark PM, Cox LJ, Fall C, Osmond C, Winter PD. Fetal and infant growth and impaired glucose tolerance at age 64. BMJ. 1991;303: 1019-22.

5. Kirchengast S, Hartmann B. Association between maternal age at menarche and newborn size. Soc Biol. 2000:47:114-26.

6. Tom SE, Cooper R, Kuh D, Guralnik JM, Hardy R, Power C. Fetal environment and early age at natural menopause in a British birth cohort study. Hum Reprod. 2010;25:791-8

7. Laitinen J, Kiukaanniemi K, Heikkinen J, Koiranen M, Nieminen P, Sovio U, Keinänen-Kiukaanniemi S, Järvelin MR. Body size from birth to adulthood and bone mineral content and density at 31 years of age: results from the northern Finland 1966 birth cohort study. Osteoporos Int. 2005;16:1417-24.

8. Martínez-Mesa J, Restrepo-Méndez MC, González DA, Wehrmeister FC, Horta $\mathrm{BL}$, Domingues MR, Menezes AM. Life-course evidence of birth weight effects on bone mass: systematic review and meta-analysis. Osteoporos Int. 2013;24:7-18

9. Valero De Bernabé J, Soriano T, Albaladejo R, Juarranz M, Calle ME, Martínez D, Domínguez-Rojas V. Risk factors for low birth weight: a review. Eur J Obstet Gynecol Reprod Biol. 2004;116:3-15.

10. Yaghootkar H. Freathy RM. Genetic origins of low birth weight. Curr Opin Clin Nutr Metab Care. 2012;15:258-64.

11. Chin RK, Lao TT. Low birth weight and hyperemesis gravidarum. Eur J Obstet Gynecol Reprod Biol. 1988;28:179-83.

12. Dodds L, Fell DB, Joseph KS, Allen VM, Butler B. Outcomes of pregnancies complicated by hyperemesis gravidarum. Obstet Gynecol. 2006;107:285-92.

13. Veenendaal MV, van Abeelen AF, Painter RC, van der Post JA, Roseboom TJ. Consequences of hyperemesis gravidarum for offspring: a systematic review and meta-analysis. BJOG. 2011;118:1302-13.

14. Asker C, Norstedt Wikner B, Källén B. Use of antiemetic drugs during pregnancy in Sweden. Eur J Clin Pharmacol. 2005;61:899-906.

15. Källén B, Mottet I. Delivery outcome after the use of meclozine in early pregnancy. Eur J Epidemiol. 2003;18:665-9.

16. Pasternak B, Svanström H, Hviid A. Ondansetron in pregnancy and risk of adverse fetal outcomes. N Engl J Med. 2013;368:814-23.

17. Matok I, Gorodischer R, Koren G, Sheiner E, Wiznitzer A, Levy A. The safety of metoclopramide use in the first trimester of pregnancy. N Engl J Med. 2009;360:2528-35

18. Sørensen HT, Nielsen GL, Christensen K, Tage-Jensen U, Ekbom A, Baron J. Birth outcome following maternal use of metoclopramide. The Euromap study group. Br J Clin Pharmacol. 2000;49:264-8.

19. Bird AL, Grant CC, Bandara DK, Mohal J, Atatoa-Carr PE, Wise MR, Inskip H, Miyahara M, Morton SM. Maternal health in pregnancy and associations with adverse birth outcomes: evidence from growing up in New Zealand. Aust N Z J Obstet Gynaecol. 2017;57:16-24.

20. Petry CJ, Seear RV, Wingate DL, Manico L, Acerini CL, Ong KK, Hughes IA, Dunger DB. Associations between paternally transmitted fetal IGF2 variants and maternal circulating glucose concentrations in pregnancy. Diabetes. 2011;60:3090-6.

21. Petry CJ, Mooslehner K, Prentice P, Hayes MG, Nodzenski M, Scholtens DM, Hughes IA, Acerini CL, Ong KK, Lowe WL Jr, Dunger DB. Associations between a fetal imprinted gene allele score and late pregnancy maternal glucose concentrations. Diabetes Metab. 2017;43:323-31.

22. Petry CJ, Sanz Marcos N, Pimentel G, Hayes MG, Nodzenski M, Scholtens DM, Hughes IA, Acerini CL, Ong KK, Lowe WL Jr, Dunger DB. Associations 
between fetal imprinted genes and maternal blood pressure in pregnancy Hypertension. 2016;68:1459-66.

23. Fisher BG, Thankamony A, Hughes IA, Ong KK, Dunger DB, Acerini CL. Prenatal paracetamol exposure is associated with shorter anogenital distance in male infants. Hum Reprod. 2016;31:2642-50.

24. Phung H, Bauman A, Nguyen TV, Young L, Tran M, Hillman K. Risk factors for low birth weight in a socio-economically disadvantaged population: parity, marital status, ethnicity and cigarette smoking. Eur J Epidemiol. 2003;18:235-43.

25. Bolin M, Åkerud H, Cnattingius S, Stephansson O, Wikström AK. Hyperemesis gravidarum and risks of placental dysfunction disorders: a population-based cohort study. BJOG. 2013;120:541-7.

26. Roseboom TJ, Ravelli AC, van der Post JA, Painter RC. Maternal characteristics largely explain poor pregnancy outcome after hyperemesis gravidarum. Eur J Obstet Gynecol Reprod Biol. 2011;156:56-9.

27. Vlachodimitropoulou Koumoutsea E, Gosh S, Manmatharajah B, Ray A, IgweOmoke N, Yoong W. Pregnancy outcomes in severe hyperemesis gravidarum in a multi-ethnic population. J Obstet Gynaecol. 2013;33:455-8.

28. Hastoy A, Lien Tran P, Lakestani O, Barau G, Gérardin P, Boukerrou M. Hyperemesis gravidarum and pregnancy outcomes. J Gynecol Obstet Biol Reprod. 2015;44:154-63.

29. Buyukkayaci Duman N, Ozcan O, Bostanci MÖ. Hyperemesis gravidarum affects maternal sanity, thyroid hormones and fetal health: a prospective case control study. Arch Gynecol Obstet. 2015;292:307-12.

30. Kuru O, Sen S, Akbayır O, Goksedef BP, Ozsürmeli M, Attar E, Saygılı H. Outcomes of pregnancies complicated by hyperemesis gravidarum. Arch Gynecol Obstet. 2012;285:1517-21.

31. Vikanes $\AA$ V, Støer NC, Magnus P, Grjibovski AM. Hyperemesis gravidarum and pregnancy outcomes in the Norwegian mother and child cohort - a cohort study. BMC Pregnancy Childbirth. 2013;13:169.

32. Behrman CA, Hediger ML, Scholl TO, Arkangel CM. Nausea and vomiting during teenage pregnancy: effects on birth weight. J Adolesc Health Care. 1990;11:418-22.

33. Temming L, Franco A, Istwan N, Rhea D, Desch C, Stanziano G, Joy S. Adverse pregnancy outcomes in women with nausea and vomiting of pregnancy. J Matern Fetal Neonatal Med. 2014;27:84-8.

34. Zhou Q, O'Brien B, Relyea J. Severity of nausea and vomiting during pregnancy: what does it predict? Birth. 1999;26:108-14.

35. Czeizel AE, Puhó E. Association between severe nausea and vomiting in pregnancy and lower rate of preterm births. Paediatr Perinat Epidemiol. 2004;18:253-9.

36. Zhang J, Cai WW. Severe vomiting during pregnancy: antenatal correlates and fetal outcomes. Epidemiology. 1991:2:454-7.

37. Weigel MM, Reyes M, Caiza ME, Tello N, Castro NP, Cespedes S, Duchicela S, Betancourt $\mathrm{M}$. Is the nausea and vomiting of early pregnancy really fetoprotective? J Perinat Med. 2006;34:115-22.

38. Koren G, Madjunkova S, Maltepe C. The protective effects of nausea and vomiting of pregnancy against adverse fetal outcome - a systematic review. Reprod Toxicol. 2014;47:77-80.

39. Berkovitch M, Mazzota P, Greenberg R, Elbirt D, Addis A, Schuler-Faccini L, Merlob P, Arnon J, Stahl B, Magee L, Moretti M, Ornoy A. Metoclopramide for nausea and vomiting of pregnancy: a prospective multicenter international study. Am J Perinatol. 2002;19:311-6.

40. Chortatos A, Haugen M, Iversen PO, Vikanes Å, Eberhard-Gran M, Bjelland EK, Magnus P, Veierød MB. Pregnancy complications and birth outcomes among women experiencing nausea only or nausea and vomiting during pregnancy in the Norwegian mother and child cohort study. BMC Pregnancy Childbirth. 2015;15:138.

41. Colodro-Conde L, Cross SM, Lind PA, Painter JN, Gunst A, Jern P, Johansson A, Lund Maegbaek M, Munk-Olsen T, Nyholt DR, Ordoñana JR, Paternoster L, Sánchez-Romera JF, Wright MJ, Medland SE. Cohort profile: nausea and vomiting during pregnancy genetics consortium (NVP genetics consortium). Int J Epidemiol. 2017;46:e17.

42. Fejzo MS, Sazonova OV, Sathirapongsasuti JF, Hallgrímsdóttir IB, 23andMe Research Team, Vacic V, MacGibbon KW, Schoenberg FP, Mancuso N, Slamon DJ, Mullin PM. Placenta and appetite genes GDF15 and IGFBP7 are associated with hyperemesis gravidarum. Nature Comm. 2018; doi: https:// doi.org/10.1038/s41467-018-03258-0.

43. Sherman PW, Flaxman SM. Nausea and vomiting of pregnancy in an evolutionary perspective. Am J Obstet Gynecol. 2002;186(5 Suppl Understanding):S190-7.
44. Crozier SR, Inskip HM, Godfrey KM, Cooper C, Robinson SM, SWS Study Group. Nausea and vomiting in early pregnancy: effects on food intake and diet quality. Matern Child Nutr. 2017;13:e12389.

45. Koren G, Madjunkova S, Maltepe C. The protective effects of nausea and vomiting of pregnancy against adverse fetal outcome-a systematic review. Reprod Toxicol. 2014;47:77-80.

46. Furneaux EC, Langley-Evans AJ, Langley-Evans SC. Nausea and vomiting of pregnancy: endocrine basis and contribution to pregnancy outcome. Obstet Gynecol Surv. 2001;56:775-82.

47. Askling J, Erlandsson G, Kaijser M, Akre O, Ekbom A. Sickness in pregnancy and sex of child. Lancet. 1999:354:2053.

48. Petry CJ, Ong KK, Burling KA, Barker P, Perry JRB, Acerini CL, Hughes IA, Dunger DB, O'Rahilly S. GDF15 concentrations in maternal serum associated with vomiting in pregnancy: the Cambridge baby growth study. BioRXIV. 2017; https://doi.org/10.1101/221267.

49. O'Rahilly S. GDF15-from biomarker to allostatic hormone. Cell Metab. 2017; 26:807-8

50. Pisa FE, Casetta A, Clagnan E, Michelesio E, Vecchi Brumatti L, Barbone F. Medication use during pregnancy, gestational age and date of delivery: agreement between maternal self-reports and health database information in a cohort. BMC Pregnancy Childbirth. 2015;15:310.

Ready to submit your research? Choose BMC and benefit from

- fast, convenient online submission

- thorough peer review by experienced researchers in your field

- rapid publication on acceptance

- support for research data, including large and complex data types

- gold Open Access which fosters wider collaboration and increased citations

- maximum visibility for your research: over $100 \mathrm{M}$ website views per year

At BMC, research is always in progress.

Learn more biomedcentral.com/submissions 